\title{
Measurement of local fluid levels and oscillation frequency on the reconstructed hydrodynamic table
}

\author{
M. Petř́ḱková ${ }^{1, a}$, P. Kryštůfek ${ }^{1, b}$ \\ ${ }^{1}$ Technical University of Liberec, Faculty of Mechanical Engineering, Department of Power Engineering Equipment, \\ Studentska 2, Liberec 1, Czech Republic
}

\begin{abstract}
The article deals with more accurate measurement of the hydrodynamic table. More accurate measurements can be realized thanks to the unique traversal device and sensor water level. Measurements can be pointwise, which was not possible until now.
\end{abstract}

\section{Introduction}

Experimental device "hydrodynamic table with low level" is used mainly to raise the visibility of flow and verification of numerical simulations. Flow was visible through visualization of particles that are applied to the surface of flowing fluid. The flowing fluid is black colored water, visualization particles is aluminium dust with a grain size $0.35 \mu \mathrm{m}$. Water colors due to the visibility of image flow on the surface. Visualization particles as a dispersion of aluminium are applied. In addition to visualization can be performed measurements of values that can be used for converting values to model the flow (flow of water) and on the work (gas flow). For conversions hydrodynamic analogy is used. This analogy is based on the similarity of flow in liquids and gases (or water flow in the channel with flat bottom and twodimensional gas flow).

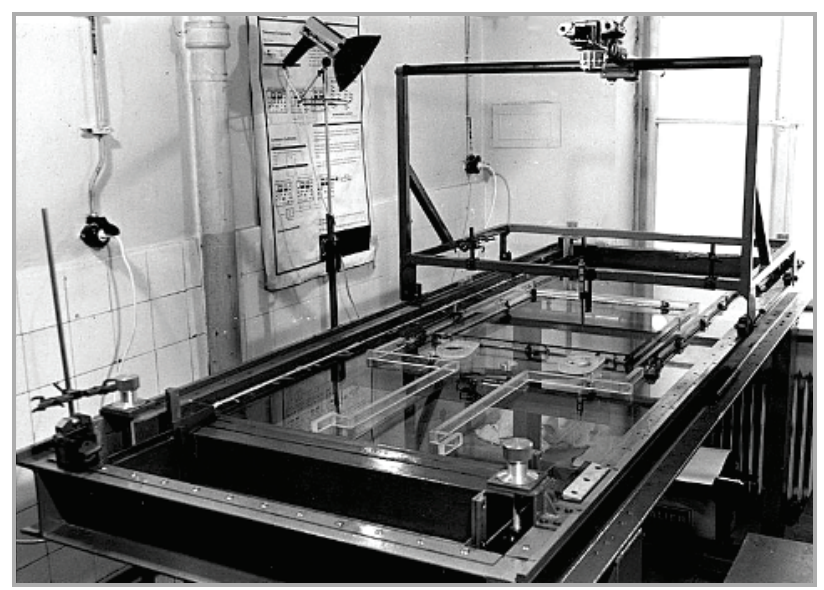

Figure 1. Hydrodynamic table - original state in 1970.

\footnotetext{
a e-mail: marketa.petrikova@tul.cz

be-mail: pavel.krystufek@tul.cz
}

Hydrodynamic table is not new in experimental fluid mechanics, but with undeniable advantages (speed, accuracy, illustration of visualization and newly accurate measurements) is used today. The first version of the hydrodynamic table was made in 1970 (shown on figure 1). The hydrodynamic table was modified in 2002. The frame of table model was reduced about $30 \mathrm{~cm}$ because the original intention shooting of experiments from below and visualisation by colors method did not prove good. High construction was complicated by the observation of the experiment above. On figure 2 is a hydrodynamic table after these adjustments. Figure 3 shows the current situation with new traversal device, consisting of two independent travels. Each travel is equipped platform with mounts for measuring equipment and accessories, scales and with fluent lock at any point option. Traversal device is provided with a scales and detents. Measuring points can be determined with an accuracy of $1 \mathrm{~mm}$ in the longitudinal and transverse directions for travel video equipment and measuring equipment.

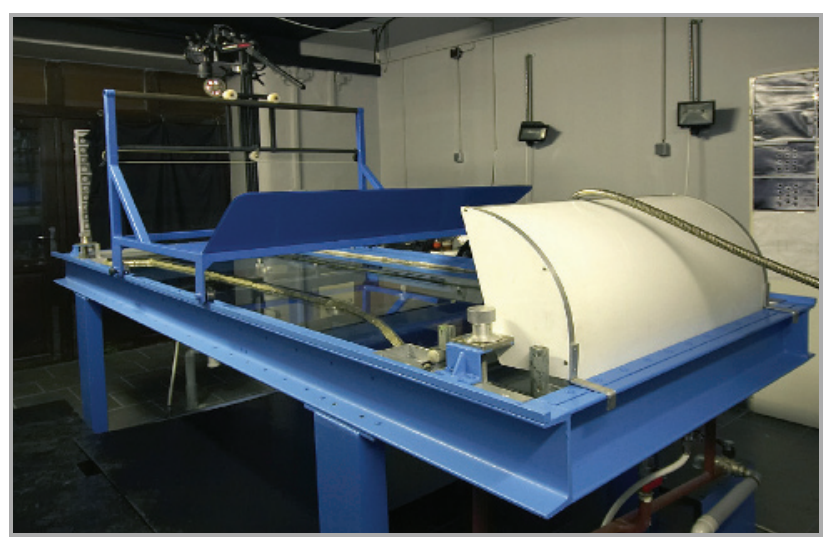

Figure 2. Hydrodynamic table after adjustments in 2007. 
To measure on the hydrodynamic table is connected water level and frequency pulsation level sensor. This sensor is used to measure the local water level and to determine the frequency oscillation of water levels. This unique measuring device (figure 4) was developed and produced in the framework of the $\mathrm{PhD}$ thesis and was registered at the Office of Industrial Property in 2010. With sensor can be measured with an accuracy of $0.01 \mathrm{~mm}$

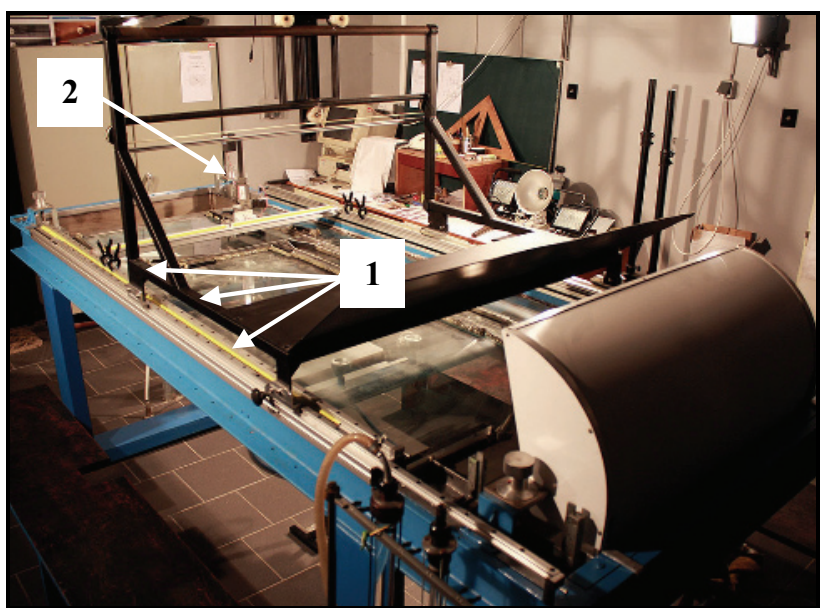

Figure 3. Hydrodynamic table - the present state; 1 - traversal device, 2 - water level and frequency pulsation level sensor

Until 2007, the hydrodynamic bath used primarily for demonstration purposes in teaching and for industrial input, level measurement as the default parameter for the application of hydrodynamic analogy was performed by micrometer, measuring point was estimated. During 2007-2013 was performed a number of experiments with two goals: to test the functional possibilities of hydrodynamic table and refine the measurement parameters for hydrodynamic analogy. Both goals are equally important. For new tasks can be selected the appropriate methodology and from the database implemented and evaluated experiments choose the same or similar cases from the conclusions resulting from the functional properties of the device. Selection of suitable methods are in some cases may appear lengthy, but also leads to reduce inefficient measurement.

Level measurement is more precise - micrometer screw (the probe tip) was first modified [9], but neither an improved the shape of the measuring tip (water suction limiting) and the digital gauges did not allow accurate measurements because it was only possible optical inspection. A significant advance was the use of acoustic signals (indicating closing of the electrical circuit of the probe contact with the water level). The gradual thinning of the ends probe has led to production of hair reduction for scan frequency pulsation levels.

Reconstruction of traversal device was completed in 2013. Existing single traversal for video was removed and in its place was placed system of rails with two mutually independent cross traversals. One of the longitudinal traverse is designed for video technology, the other is specially shaped platform (is shown on figure 6) for measuring devices: sensor (measuring the water level and frequency of pulsation), dial gauge and drawing equipment (building model kits), probe (measuring speed), etc.

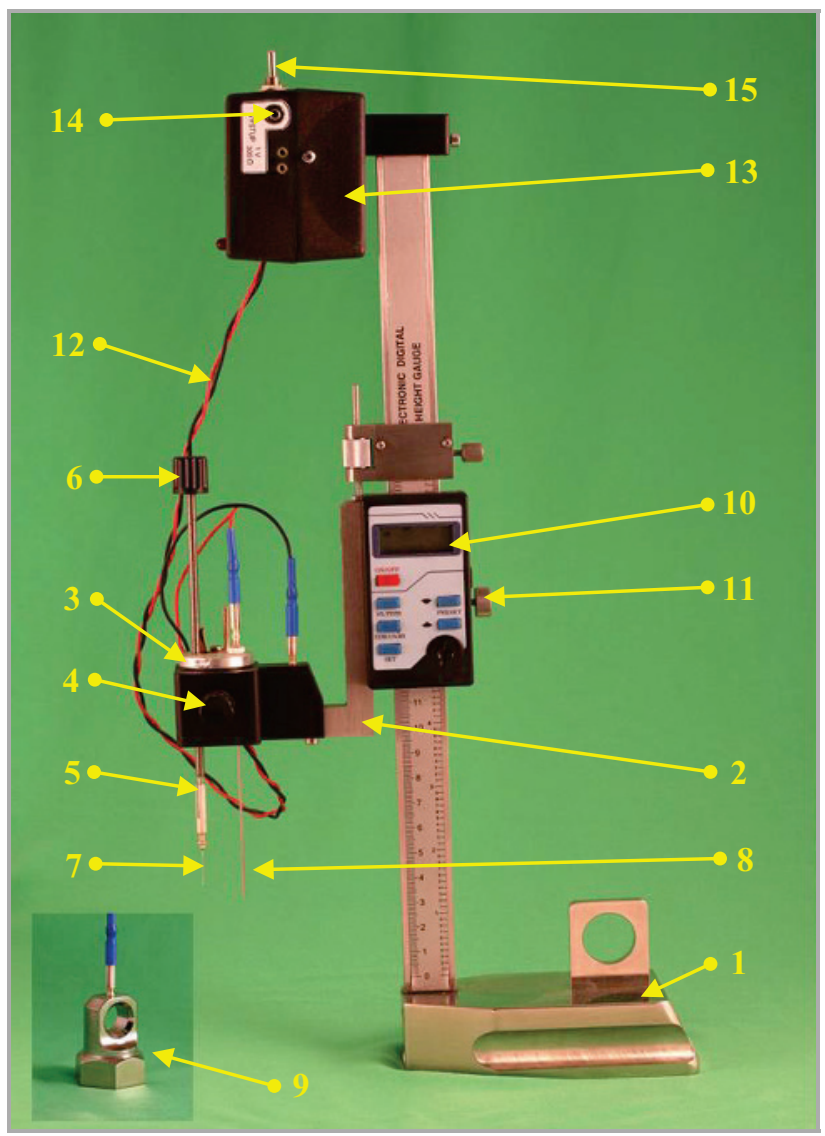

Figure 4. Water level and frequency pulsation level sensor 1 -base, 2 -carrier of measuring electrodes, 3 -element of positioning of electrodes, 4 -setscrew of positioning of electrodes, 5-adjustable measuring electrode, 6-isolated wheel measuring electrode, 7 - hair reduction for measuring of the frequency oscillation, 8 -telescopic electrode, 9-free electrode, 10 - values indicator, 11 - setscrew of measuring electrodes carrier and values indicator, 12 - wires, 13 - optoacoustic signal source, 14 - output of signal, 15-switch of signal source.

"Discovery" of hair reduction brought significant more accurate measurement. It was possible to find places (points) with a minimum liquid level and the maximum level. Detail of the sensor tip and hair reduction is shown on figure 5 .

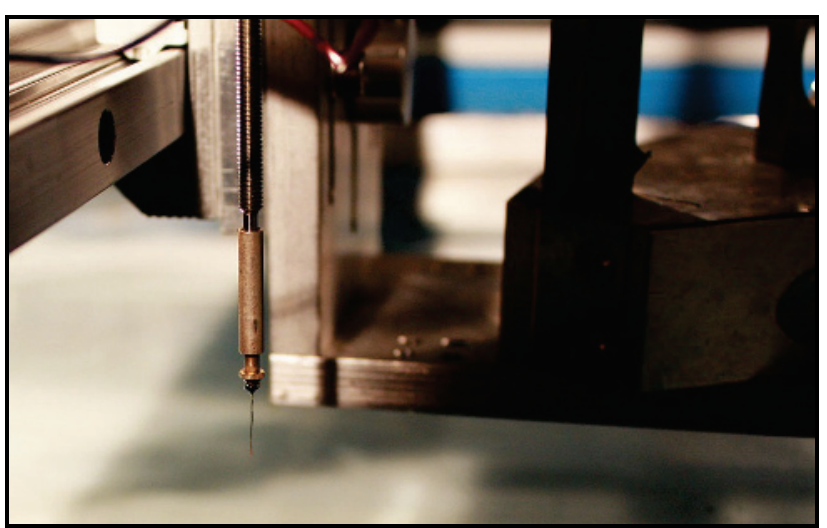

Figure 5. Detail of the sensor tip and hair reduction. 


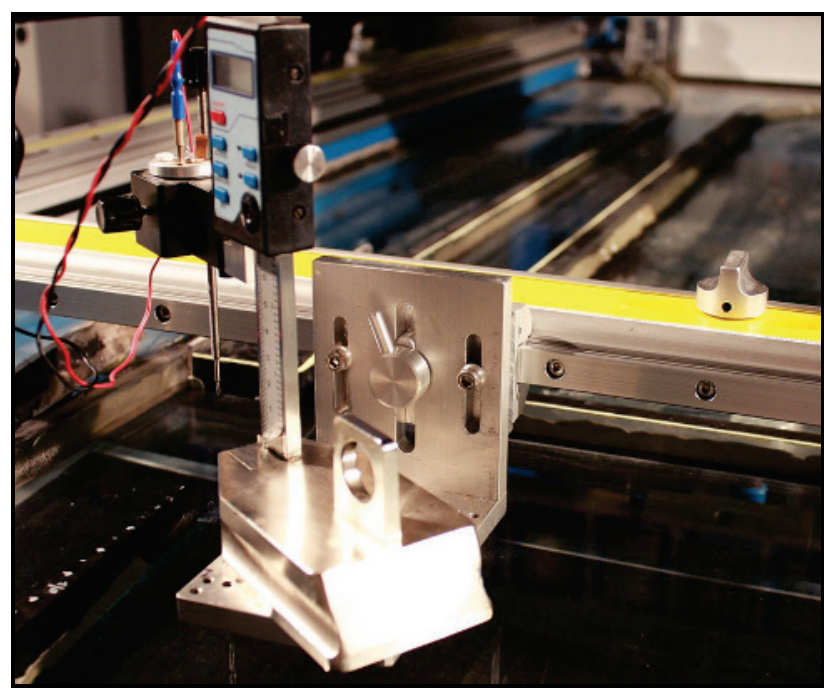

Figure 6. Detail of platform with bolt sensor.

\section{Description of experiment assembly}

The model assembly is formed from rectangular hollow with constant width and variable length. The water supply to the model assembly is implemented through the inlet channel of constant cross section. The channel is terminated by nozzle. Against the nozzle is located eccentrically cavity. The cavity is partially open. Space between the nozzle and the cavity is used to outflow water from the cavity. After passing through the model assembly water flows out into the space with shaped borders. It used to direct the reflected waves outside the experiment. Model assembly is shown on figure 7 .

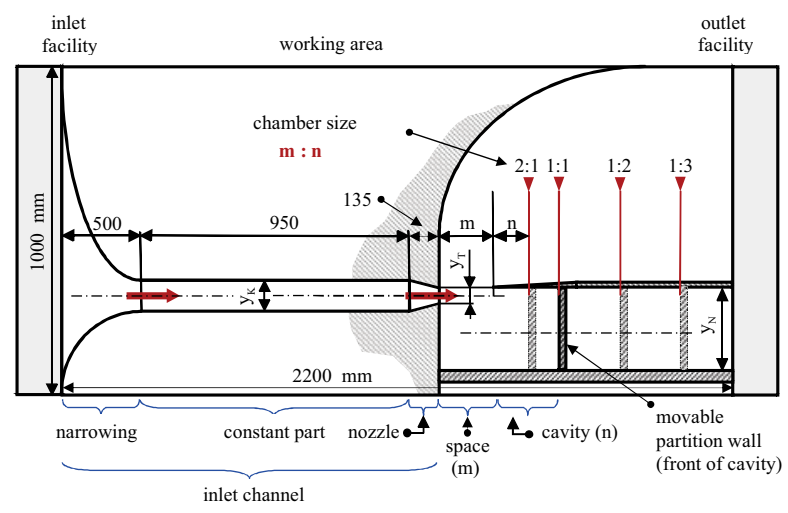

Figure 7. Scheme of the model assembly.

Dimension $m$ is the distance between nozzle outlet and the upper corner of the cavity - a space that leads to emptying the cavity. Dimension $n$ is length of the cavity; $y_{K}$ is width of the inlet channel; $y_{T}$ is width of nozzle at the end of inlet channel, $y_{N}$ is width of the cavity and $m: n$ is ratio of space and length of cavity.

\section{Objective of the experiment}

The aim of the experiment is the excitation pulses in the cavity, respectively in the space between the nozzle and the cavity. The water flow in the inlet channel has no pulse character and stream behind the nozzle has a pulsed character. Pulse character is due to changes in the direction of flow - alternating direction in the cavity and outwards. Periodic changes of flow behind the nozzle are characterized by pulse frequency. This frequency can be measured by frequency sensor. During the experiment a local minimum and maximum of pressure level height produced which can be used to identify by probe. Their location can be determined from scales of traversal device.

From the measured frequency in the water may be determined the conversion rate in the air and compared with the defined values of chamber "a" or possibly other octaves. Measuring point is shown in figure 8 and is located midway between nozzle and sharp edge. From the measured displacements of pulsating levels can be fluctuations of air pressure at a given location or acoustic pressure determined. Measuring points are shown in figure 9 and they are midway between the axis of the nozzle - sharp edge. Points outside of the cavity are identified by positive numbers; points in the cavity are identified by negative numbers.

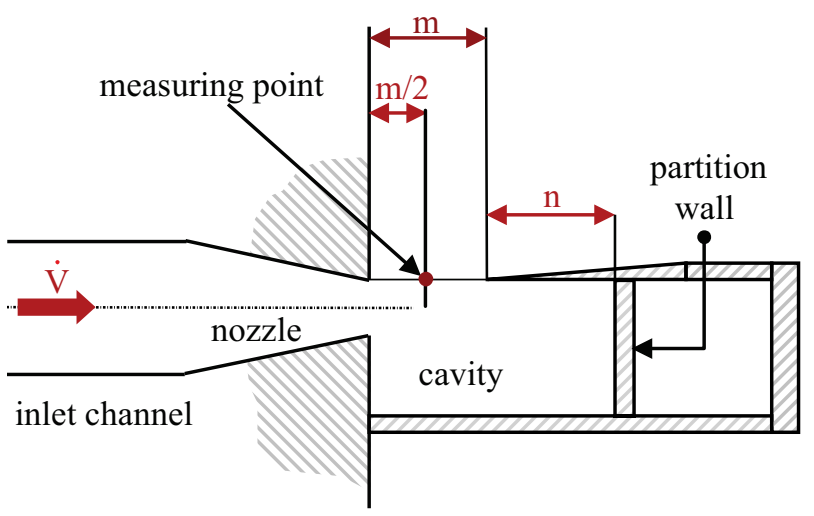

Figure 8. Measuring point for measurement of frequency of pulsation levels.

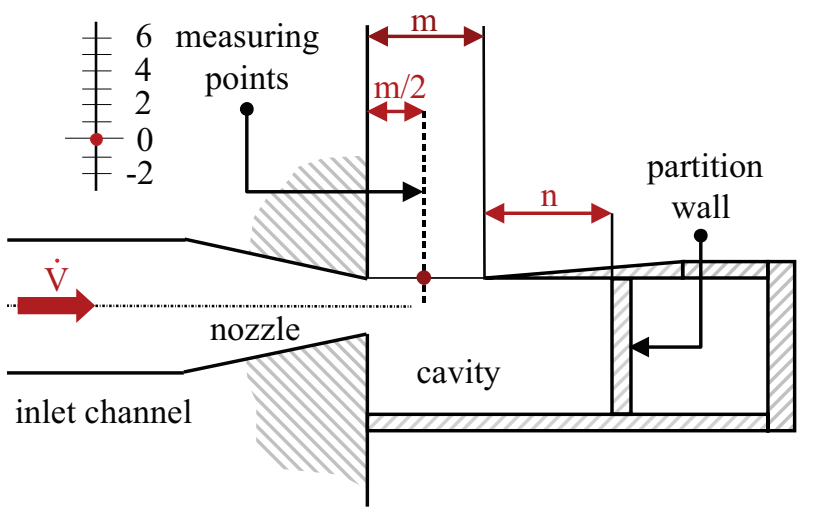

Figure 9. Measuring points for measurement of pulsating levels frequency.

\section{Experiment and measurements}

The experiment was performed for the values $y_{K}=86 \mathrm{~mm}$ (width of the inlet channel), $y_{T}=20 \mathrm{~mm}$ (width of nozzle), $y_{N}=92 \mathrm{~mm}$ (width of the cavity), $m=140 \mathrm{~mm}$ (space), variable $n=0 \div 400 \mathrm{~mm}$ (length of cavity) and $\dot{V}=[100,200,300,400,500] l h^{-1}$ (flow rate). 
Traversal device allows accurate determination of the measurement points. To measure was chosen a spot in the middle of the field and was identified the specific measurement points. This spot is shown in figure 10 and figure 11. On figure 10 stream of water is directed into the cavity - cavity is filled. On figure 11 stream of water is directed out of the cavity - cavity is emptied. Selection of the measurement place (red area) was based on the observation diversion of flow (blue arrows). The first was measured level as the other was measured frequency. In measuring were identified local extremes of fluid levels ( $h \_$max and $h \_$min) and subsequently were evaluated the maximum displacement of fluid level $(\Delta h)$. Measurements were made from point " 0 " toward the cavity (negative signs on the scale of measurements indicate the direction upstream) and outwardly from the cavity (positive sign means the direction of the same direction as the flow). In measuring of fluid levels inside the cavity was measured only two points. Other points do not have importance due to the size of the model and the inlet nozzle. In measuring outside of the cavity was measured on the positive scale until the pulsation $(\Delta h)$ in the three of consecutive holding points ceased to change significantly. Measurement of values $\Delta h$ should be determined "ideal" point to measure of the frequency.

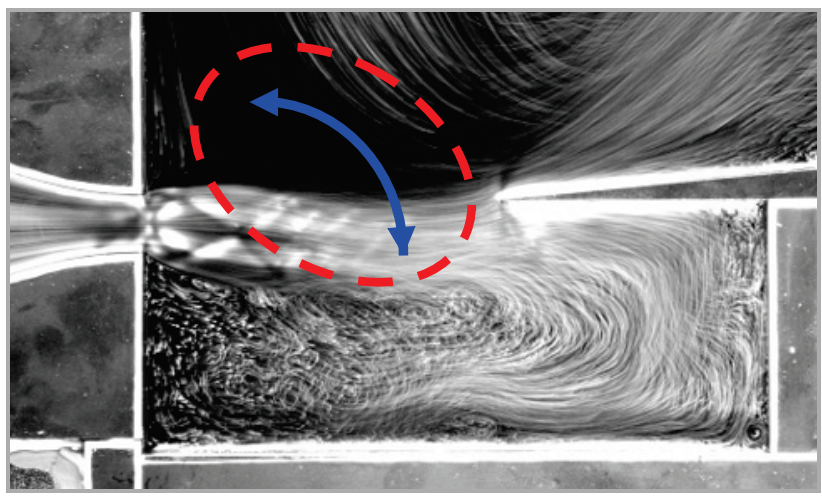

Figure 10. Measurements are before building traversal device cavity is filled.

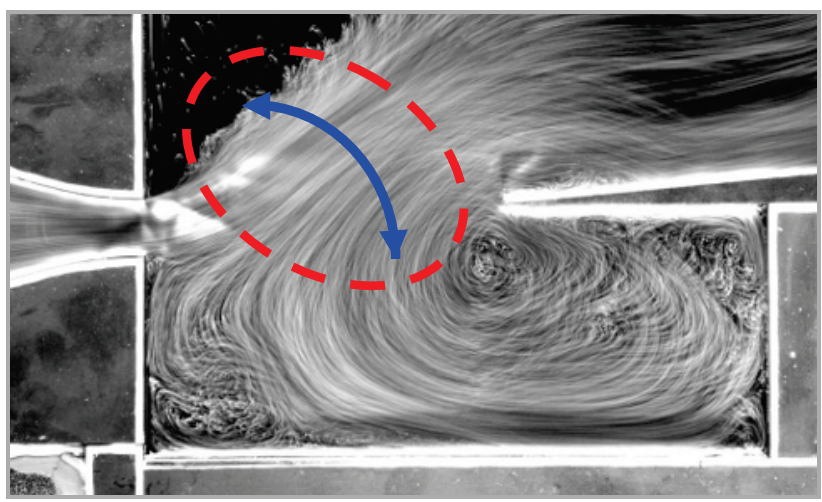

Figure 11. Measurements are before building traversal device cavity is emptied.

\section{Results}

The results of measurements of deflections height pulsating level are shown in figure 12. The curves show that the maximum of pulsation is on the line connecting nozzle-sharp edge that is in point " 0 ". By this it is clear that the magnitude of displacement is increased in proportion with the speed of influx.

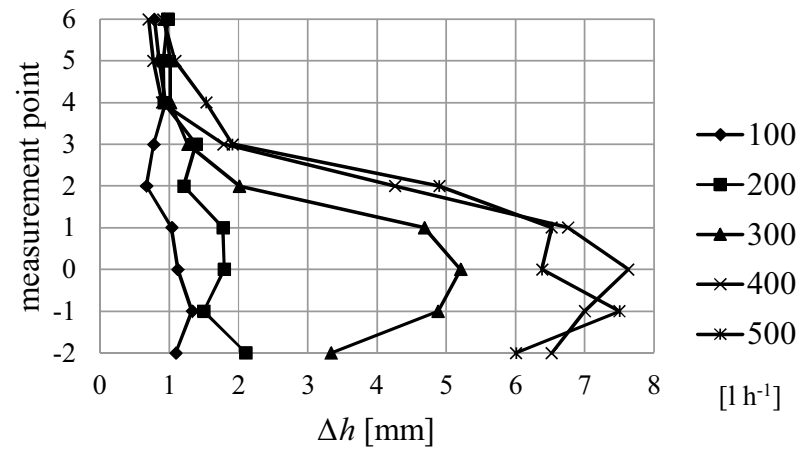

Figure 12. The deflections height of pulsating level.

Measurement of frequencies were carried out at a single point " 0 " and subsequently evaluated in the charts. The dependence of pulsation of water level frequency $(f M)$ at mean speed in the nozzle $\left(w_{-} m\right)$ is shown in figure 13. The mean velocity in the nozzle was determined by calculating from the equation of continuity, which flow profile corresponds to multiplication of width of the nozzle and the level height in the nozzle. The level height in the nozzle was measured for the individual volume flows. The graph shows that the individual curves have an increasing trend (the curve of the Strouhal number dependence on Reynolds). Values of frequencies for $n<6$ have a different course, for such a small size would be desirable to narrow down the nozzle - the width of the inlet flow is unreasonable for these geometries.

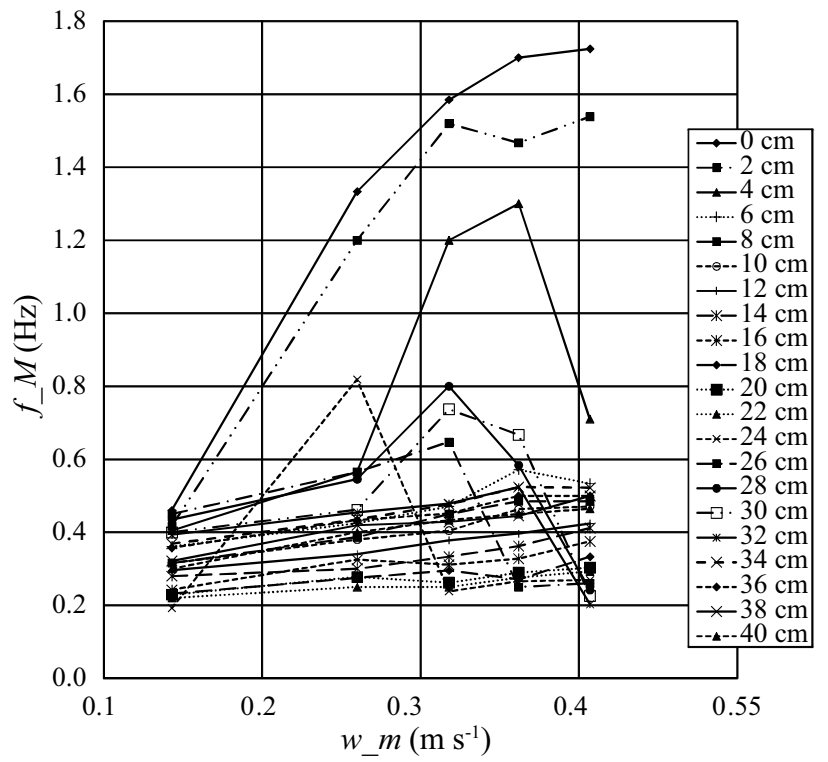

Figure 13. The dependence of frequency $\left(f_{-} M\right)$ at mean speed in the nozzle $\left(w_{-} m\right)$.

The following figure 14 shows the graphical dependence of the frequency $f_{-} M$ on the length of the cavity. From dependence follows that during the changes of length of the cavity occurs suddenly to step change in the frequency value. This leap occurs when the ratio of $m: n=1: 2$ (the length of the cavity is 2 times larger than the distance of the cavity from the nozzle). 


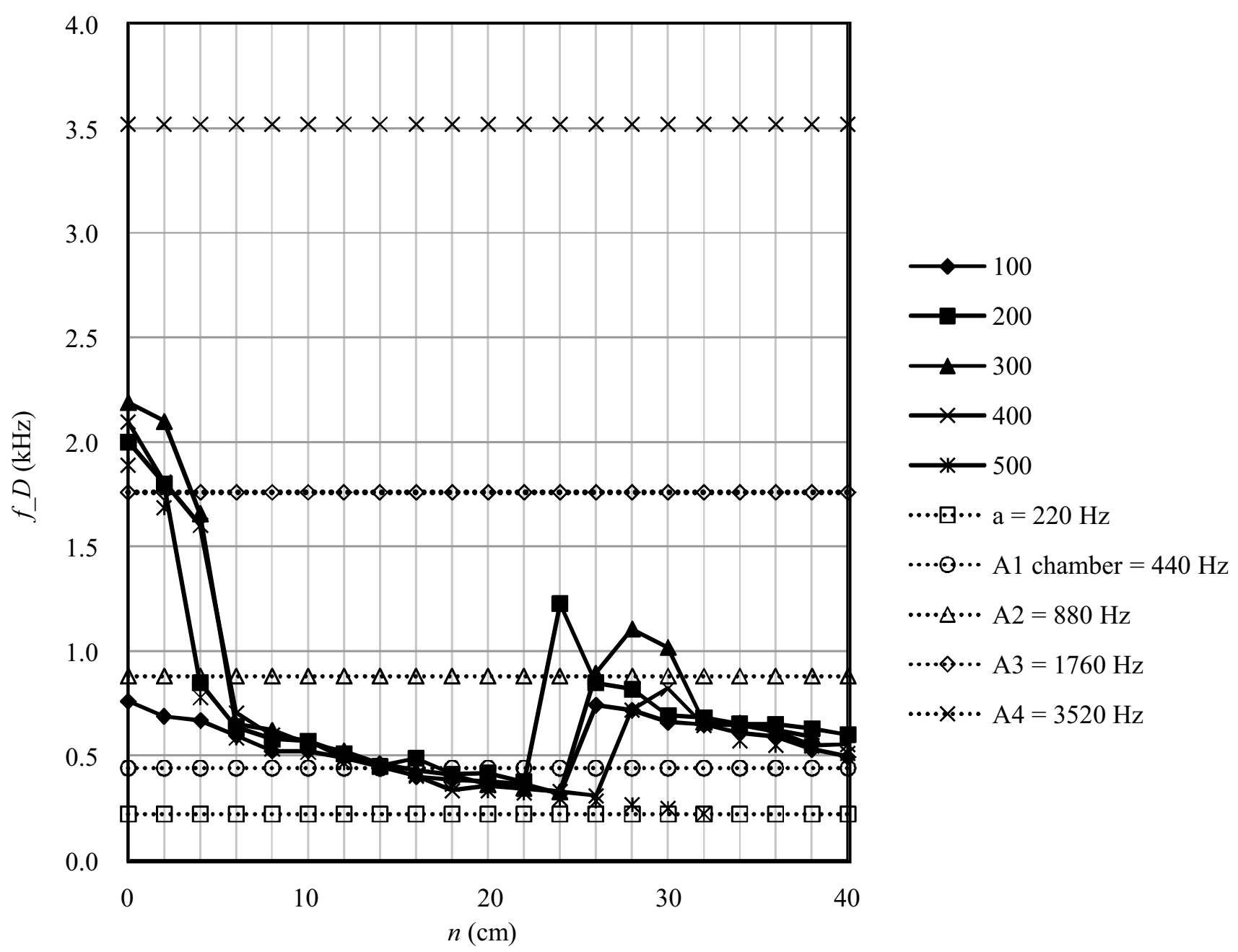

Figure 15. The dependence of frequency $f_{-} D$ on the length of the cavity.

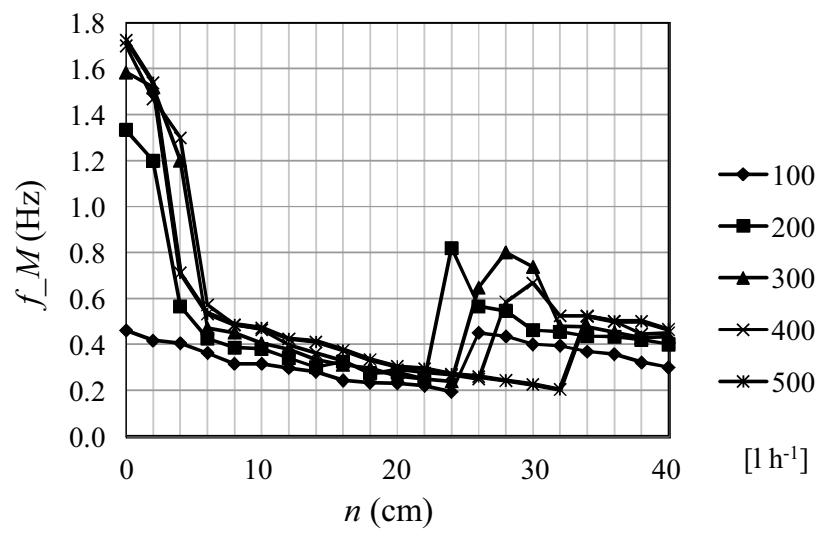

Figure 14. The dependence of the frequency $f_{-} M$ on the length of the cavity.

If you convert the frequency of water $f_{-} M$ into the air $f \_D$ can be concluded that the geometrically similar model when changing the length of cavity occur the step change, the corresponding increase in the tone of approximately one to two octaves. It is not of course a pure octave. The graph in figure 15 shows that the size of leap depends on intensity of inlet medium.

\section{Conclusion}

On previously realized experiment "filling asymmetrically situated cavity" [1-3], [5] is shown benefit of "reconstruction of hydrodynamic table". This is a shift in the quality and in quantity: easy, quick and precise manipulation of individual travels of traversals device, simple determination of the measurement points. It is shown here measurement of in a number of points consecutively. It can be also applied to various types of networks or points on the curves. Accuracy of measurement can be increased by moving closer to the measurement point in the vertical direction. This allows adjustable platform. All geometry (parameters of model assembly, measuring points, etc.) can be checked by dial indicator at any time.

The measurement results of the model can now be better compared with the work, because the experiments are repeatable and can get much more data than it was in the past. 


\section{Acknowledgements}

This work was financially supported by the particular research student grant SGS 28000 at TU of Liberec.

\section{References}

1. M. Petříková, P. Peukert, P. Kryštůfek, Machine Design, 4, 213-218 (2012)

2. P. Kryštůfek, M. Petrríková, Exp. fluid mechanics, 367-370 (2012)

3. M. Petříková, P. Peukert, P. Kryštůfek, KOD, 439444 (2012)

4. M. Petř́ková, P. Peukert, J. Unger, Exp. fluid mechanics, 390-393 (2011)

5. P. Kryštůfek, M. Petř́iková, Set. Kat. Mech. Tek. a term., 187-190 (2011)

6. M. Petř́iková, M. Vereš, Machine design, 103-106 (2010).

7. M. Petrríková, J. Kneř, P. Jerje, Certificate of registration of a utility model, $\mathrm{CZ}$, Industrial Property Office, Registration No. 21409, recorded October 25, 2010

8. M. Petř́íková, V. Dvořák, M. Vereš, Scien. Proc., 153-160 (2009)

9. M. Petř́ḱková, J. Unger, Exp. fluid mechanics, 273278 (2009)

10. M. Petř́iková, P. Peukert, J. Unger, Exp. fluid mechanics, 279-286 (2009)

11. M. Petŕíková, Ph.D. thesis (2008)

12. P. Kryštůfek, M. Petříková, Exp. fluid mechanics, 98-108 (2008)

13. M. Petř́ková, P. Kryštůfek, Mechanical engineering, CD-ROM (2008)

14. M. Petříková, Exp. fluid mechanics, 111-119 (2007)

15. M. Petř́ḱková, P. Kryštůfek, J. Kneř, Mechanical engineering, CD-ROM (2007) 